\title{
Differential profiling analysis of proteins involved in anti-proliferative effect of interferon- $\alpha$ on renal cell carcinoma cell lines by protein biochip technology
}

\author{
KOGENTA NAKAMURA $^{1}$, KAZUHIRO YOSHIKAWA ${ }^{2}$, YOSHIAKI YAMADA ${ }^{1}$, SHINSUKE SAGA ${ }^{2}$, \\ SHIGEYUKI AOKI ${ }^{1}$, TOMOHIRO TAKI ${ }^{1}$, MOTOI TOBIUME ${ }^{1}$, TORU SHIMAZUI ${ }^{3}$, \\ HIDEYUKI AKAZA ${ }^{3}$ and NOBUAKI HONDA ${ }^{1}$
}

\author{
Departments of ${ }^{1}$ Urology and ${ }^{2}$ Pathology, Aichi Medical University School of Medicine, Aichi; \\ ${ }^{3}$ Department of Urology, Institute of Clinical Medicine, University of Tsukuba, Tsukuba, Japan
}

Received September 28, 2005; Accepted November 14, 2005

\begin{abstract}
Interferon- $\alpha$ (IFN) is widely used for the treatment of progressive renal cell carcinoma (RCC), but its effective response rate is only about $15 \%$. New biomarkers of RCC contributing to the effective IFN treatment are needed to establish a sensitivity test for evaluating if the IFN is effective or not against RCC. All the proteins expressed in the IFNsusceptible and -resistant RCC cell lysates were analyzed by surface enhanced laser desorption inonization (SELDI) mass spectrometry using ProteinChip ${ }^{\circledR}$ technology and their different protein expression were detected by the comparison of the profiles between them. We detected the following candidate markers that exhibited peak shifts: a) in the IFNsusceptible cell lines, a candidate marker with a molecular weight of $5688 \mathrm{Da}$ was detected on a hydrophobic (H4) chip: b) in the IFN-resistant cell lines, candidate markers each with a molecular weight of 8049, 3157, 3993, and 8959 Da were detected on strong anion exchange (SAX2, pH 9.0, two types) chips, $\mathrm{H} 4$ chip, and weak cation exchange (WCX, pH 9.0) chips, respectively. IFN treatment produced no weight increase in these four proteins, and c) candidate marker with a molecular weight of 1623 Da that was expressed in both cell lines after the IFN treatment was detected on the H4 chip. These data suggest that the ProteinChip system is very useful in identifying proteins showing unique peaks in the RCC cell lines with different IFN susceptibility, and the comparison of these proteins measured in RCC cell lysates may help to identify the IFN sensitivity. Furthermore, the discovery of a
\end{abstract}

Correspondence to: Dr Yoshiaki Yamada, Department of Urology, Aichi Medical University School of Medicine, Nagakute-cho, Aichi 480-1195, Japan

E-mail: 101959@gk.amu.aichi-med-u.ac.jp

Key words: renal cell carcinoma cell lines, interferon- $\alpha$, antiproliferative, SELDI susceptibility and or a inhibitory factor may eventually lead to the development of a novel drug targeting the respective factor for the improvement of anticancer chemotherapy.

\section{Introduction}

Renal cell carcinoma (RCC) is a relatively common tumor, accounting for approximately $3 \%$ of adult malignancies (1). While the number of occasions in which cancer is discovered incidentally has increased owing to prevalence of health check-up and ultrasonography, the number of cases with distant metastasis has not decreased. Early detection and early surgical resection are said to be effective against carcinoma such as gastric cancer. On the other hand, the 5-year survival rate of advanced RCC cases such as those with metastasis, unresectable cases, and recurrence cases is $\leq 5 \%$ (2). Interferon- $\alpha$ (IFN) is widely used for the treatment of such advanced renal cell carcinoma, but, its response rate is low; approximately $15 \%$ (3). The behavior of IFN remains largely unknown, but the following is speculated; IFN activates the patient's immunoreactivity enhancing anti-tumor immune capacity, and IFN acts directly on the renal cell carcinoma to control the proliferation of the cells or cause apoptosis. However, as there is currently no chemotherapeutic agent effective against renal cell carcinoma, IFN is used irrespective of the sensitivity. IFN is expensive and has side effects such as influenza-like symptoms, psychoneurosis symptoms, leukopenia/thrombocytopenia, and pneumonitis. Thus, discovery of markers related to IFN sensitivity, which can be used to decide whether or not to administer IFN, is awaited.

In recent years, with the progress in molecular biology most of the sequences in the human genome have been identified. In addition, specific genes expressed in various cells and tissues have been found and the mechanism of carcinogenesis has been revealed. Markers of the drug efficacy have been found by cDNA microarray analysis using the expressed genes (mRNA). However, analysis of proteins in cells and tissues in varying conditions is indispensable to determine the functions of the proteins expressed in the cells or of the modified 
proteins after expression. This analysis is done by creating the expression profile by two-dimensional electrophoresis or by carving out the characteristic spots from the gel and the mass spectrometry of the protein contained in the above-mentioned spots. However, there remain issues to be solved with two-dimensional electrophoresis such as the reproducibility and throughput (4), and thus technologies best suited for easy analysis and high throughput have been developed. As a result, the new ProteinChip System attached to the sample tray of the mass spectrometry itself has been developed $(5,6)$. This ProteinChip System enables exhaustive profiling of proteins in various cells or specimens such as serum and thus it has become feasible to detect and compare proteins affected by cancer cells and drugs (7-13). Thus, this system is rapidly gaining popularity. In the urological field, it is also being used for detecting new biomarkers using serum obtained from patients suffering from prostate cancer $(8,12,13)$. In this study, we searched for proteins related to the effect of IFN therapy in controlling the proliferation of cells of human RC cell strains, and which could be used for predicting the effect of IFN therapy.

\section{Materials and methods}

Tumor cell lines and anti-proliferation assay. Human RCC cell lines (15 cell lines), provided by Dr L.J. Old (MemorialSloan Kettering Cancer Center, USA), were used in this study. The cells were cultured with RPMI-1640 medium (Sigma, MO, USA) containing $10 \%$ inactivated fatal bovine serum (IBL, Gunma, Japan), $100 \mathrm{U} / \mathrm{ml}$ of penicillin, and $0.1 \mathrm{mg} / \mathrm{ml}$ of streptomycin, at $37^{\circ} \mathrm{C}$ under an atmosphere of $5 \% \mathrm{CO}_{2}$.

Human RCC cell lines were seeded in a 96-well $\left(5 \times 10^{4}\right.$ cells per well) flat-bottom plate (Falkon 3072, Beckton-Dickinson, USA) with various concentrations $(0,1000,3000,10,000 \mathrm{U} / \mathrm{ml})$ of IFN- $\alpha$ (Otsuka, Tokyo, Japan) and cultured at $37^{\circ} \mathrm{C}$ under an atmosphere of $5 \% \mathrm{CO}_{2}$. The number of cells was compared using a WST-1 assay Kit (Cell Counting Kit, Dojindo, Kumamoto, Japan) 5 days after onset of culture to determine the cytostatic effect of IFN.

Briefly, $10 \mu 1$ of WST-1 reagent prepared in accordance with an attached protocol was added to each culture well. The cells were cultured for 3 additional hours and directly evaluated the color reaction with a 96-well plate reader (Tohso, Micro Plate Reader, Tokyo, Japan). Based on the results, two IFN-sensitive and two IFN-resistant cell lines were chosen and used for the following experiments.

Protein sample preparation. IFN-sensitive and IFN-resistant cell lines were cultured in a Falkon T-75 flask. Samples were collected macroscopically at $80 \%$ confluence. For treatment with IFN, we used IFN at a final concentration of 10,000 $\mathrm{U} / \mathrm{ml}$ and the exposure was for $10 \mathrm{~min}$ at $37^{\circ} \mathrm{C}$. Monolayer cells were first washed with PBS and added to $2 \mathrm{ml}$ of cell lysis solution (9 M Urea/2\% CHAPS/1 mM DTT) in a flask, from which cells and supernatant were collected. The sample solution was then sonicated with a sonicator (Heat SystemUltrasonics, Inc. and Sonifier Cell Distruptor, Plaiview, NY, USA) at $50 \mathrm{~W}$ for $30 \mathrm{sec}$. Then, the sample solution was centrifuged at $10,000 \mathrm{x} \mathrm{g}$ for $10 \mathrm{~min}$ to remove insoluble materials and stored at $-80^{\circ} \mathrm{C}$ until use. The protein level in the cell lysis solution was measured and conditioned with cell lysis solution to make an identical concentration.

ProteinChip array analysis. ProteinChip surface enhanced laser desorption ionization (SELDI) technique consisting of functional processing chips and (ionization)-time-of-flight mass spectrometry each chip was used to analyze proteins exhaustively. Time-of-flight spectra of protein attached to each chip were measured and analyzed. Four types of functional chips such as anion exchange chip (SAX2), cation exchange chip (WCX2), nickel combined chip (IMAC3-Ni) and hydrophobic chip (H4) (Ciphergen Biosystems Inc., CA, USA) were used to analyze as many proteins with different features as possible. In order to separate the protein mixture by the use of their ionic strengths and to facilitate the analysis of proteins with the SELDI technique, the protein mixture was diluted with $50 \mathrm{mM}$ Tris- $\mathrm{HCl}(\mathrm{pH} 9.0)$ or $50 \mathrm{mM}$ sodium acetate, and applied to the SAX2 chip, which was then rinsed with each wash buffer used for the sample dilution. In the application of the sample to the WCX2 chip, the protein mixture was diluted and rinsed with $50 \mathrm{mM}$ sodium acetate ( $\mathrm{pH} 4.5)$ or $50 \mathrm{mM}$ sodium phosphate $(\mathrm{pH} 6.0)$. The protein mixtures applied on the IMAC3-Ni and the H4 chips were washed with PBS and Milli-Q water, respectively.

Protein sample solution $(30 \mu 1)$ dissolved at the final protein concentration of $779.2 \mu \mathrm{g} / \mathrm{ml}$ in cell lysis buffer was diluted 5-fold with appropriate wash buffer for each chip SAX2 (pH 9.0), WCX2 (pH 6.0), and IMAC3-Ni (PBS). Then $150 \mu \mathrm{l}$ of the diluted sample solution was applied to each chip, and incubated at room temperature for $15 \mathrm{~min}$. Then each chip was washed 3 times with the wash buffer used for the sample dilution.

After drying the chip, $0.5 \mu 1$ of the energy absorption molecule (EAM) solution containing sinapic acid, 50\% acetonitrile and $0.5 \%$ trifluoroacetic acid (SPA) was applied to the chip, then dried by flushing cold air. Subsequently, the sample on the chip was analyzed by using the Protein Biological System II mass spectrometer reader (Ciphergen Biosystems, Inc.). In the analysis of the protein sample with the $\mathrm{H} 4$ chip, $2 \mu \mathrm{l}$ of the protein sample solution $(779.2 \mu \mathrm{g} / \mathrm{ml})$ was applied to the chip, and washed with Milli-Q water. The sample was dried and analyzed by using the Protein Biological System II mass spectrometer reader after two additions of $0.5 \mu 1 \mathrm{SPA}$. The measurements using SAX2, WCX2, and IMAC2-Ni chips were performed with duplicate samples. The obtained peak spectra were analyzed by using the Proteinchip Software Version 2.1b (Chiphergen Biosystems Inc.).

Database analysis of expressed proteins. We searched for proteins with similarly expressed molecular weights using SWISS-PROT of ExPASy Molecular Biology Server. As a condition of the search, the error range of molecular weight (MW) was within $1 \%$.

\section{Results}

IFN sensitivity test of renal carcinoma cell lines. Using 15 cell lines of human RC, we evaluated the sensitivity to IFN with WST-1 assay (Fig. 1). The sensitivity to IFN differed 


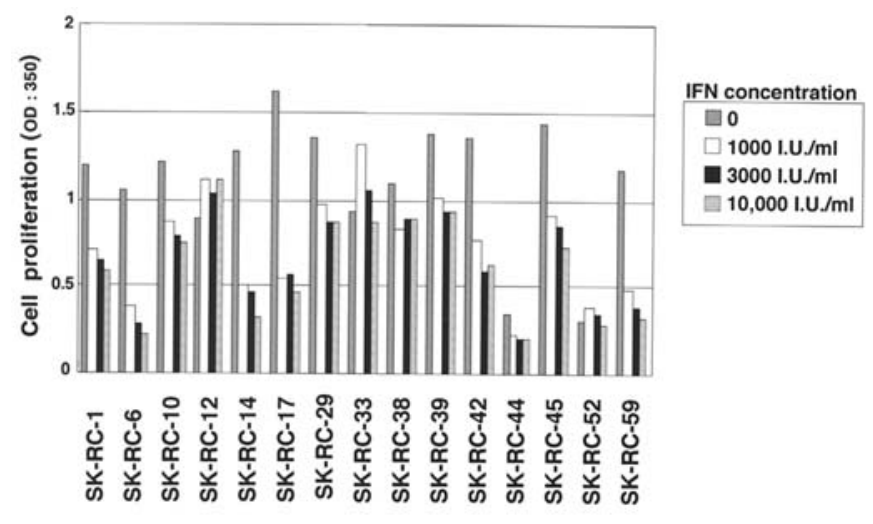

Figure 1. Relationship between the dose of IFN- $\alpha$ and the cell growth of 15 renal cell cancer cell lines. Five thousand cells of 15 cell lines was inoculated into each well of Falcon multiple well plate and cultured in the medium containing IFN- $\alpha$ at $0,1000,3000$ and 10,000 units $/ \mathrm{ml}$, respectively. The number of cells in each well was evaluated 5 days after inoculation, using WST-1 assay.

\section{IMAC-Ni chip}

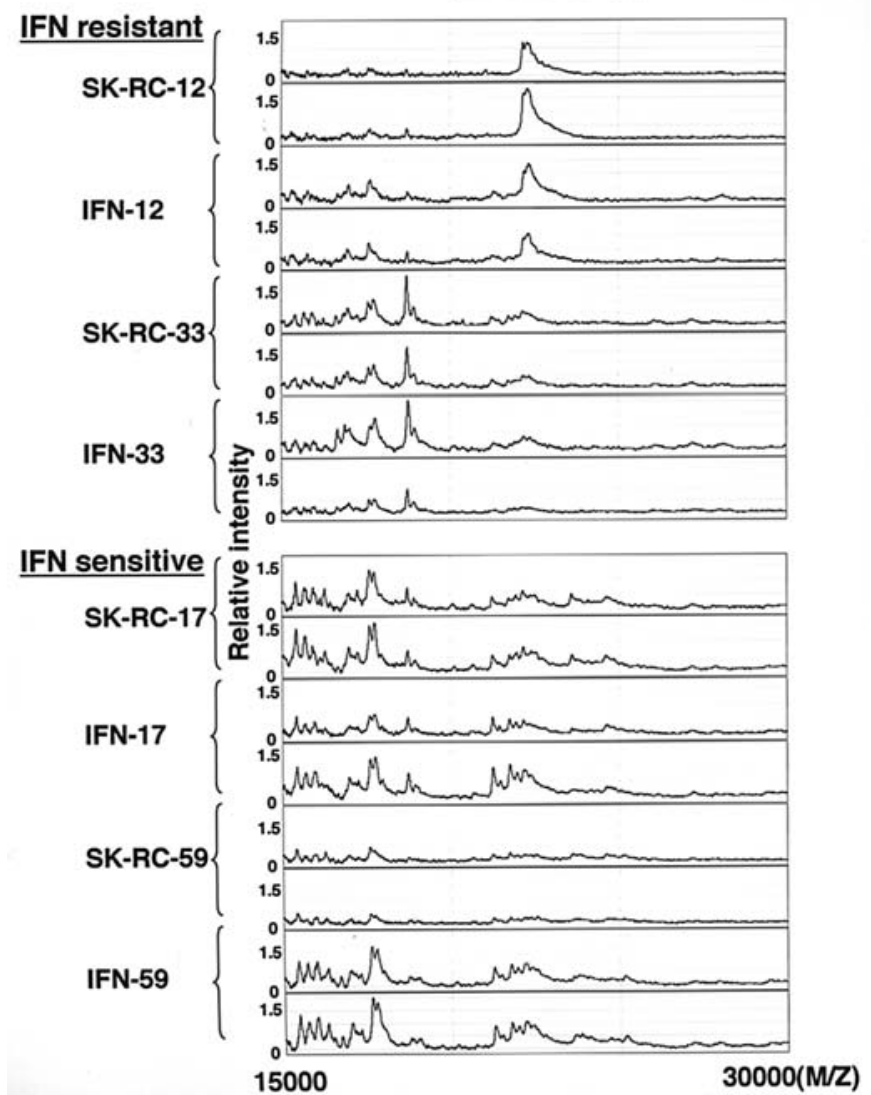

Figure 2. Measurement of the proteins in the cultured renal cell lysates by ProteinChip analysis using SELDI-TOF. The stability and reproducibility of this assay system are shown in the representative spectrum examples obtained from SELDI analysis of the cultured renal cell lysate samples bound to the IMAC-Ni ProteinChip array, in which similar profiles were obtained from duplicate assays. IFN-12, -33, -17 and -59 indicate the cell lysate samples obtained from cells of SK-RC-12, -33, -17 and -59, respectively, after treatment with IFN. M/Z, mass/charge.

between the cell lines. We examined the protein expression of two sensitive cell lines (SK-RC 17, 59) and two resistant cell lines (SK-RC 12,33), selected for ease of culture.

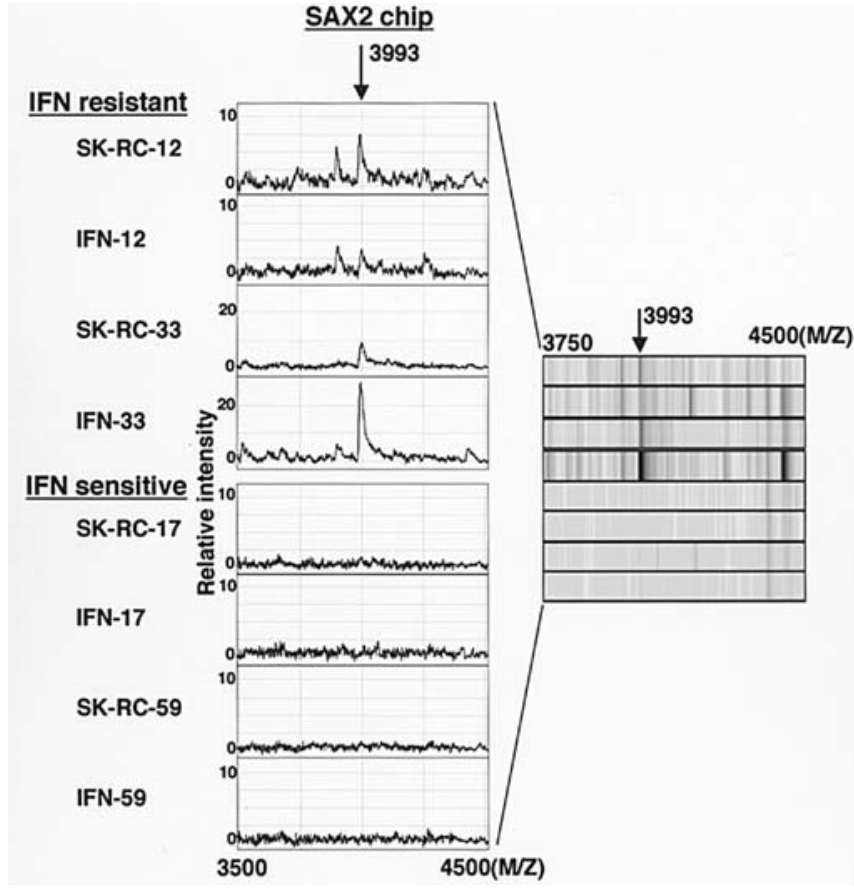

Figure 3. Representative spectrum examples from SELDI analyses of cultured renal cell lysate samples bound to a SAX2 ProteinChip array. The spectrum is represented as a mass chromatogram (left) or a density plot (right). A peak of $3993 \mathrm{Da}$ (arrow) was present in the four IFN-resistant cell lysate samples but absent in the four IFN-sensitive samples. IFN-12, -33, -17 and -59, indicate the cell lysate samples obtained from cells of SK-RC-12, -33, -17, and -59, respectively, after treatment with IFN. M/Z, mass/charge.3

SELDI profiling of RCC cell lysates. Various functional chips and a mass spectrometer were used to create profiles of proteins expressed in RC cell lines. First to confirm the reproducibility of the measurement, we measured duplicates and compared the results. Fig. 2 illustrates the results of the evaluation using the IMAC3-Ni chip. The measurement was repeated twice and similar patterns were obtained. Relatively stable reproducibility could be confirmed by the measurement.

We studied the proteins with different characteristics by adding to 4 types of chips, SAX2, WCX2, IMAC3-Ni and $\mathrm{H} 4$, after washing with buffer at $\mathrm{pH} 9.0, \mathrm{pH} 6.0, \mathrm{PBS}$ and water, respectively. The obtained profiles were compared only for the peaks observed commonly in the two sensitive cell lines and two resistant cell lines.

Four characteristic proteins were observed in the resistant cell lines; proteins with MW of 3993 (Fig. 3) and 3157 (Fig. 4) in SAX2 chips, a protein with MW of 8959 (Fig. 4) in WCX2 chips and that with MW of 8943 in H4. There was no change in the peak of the four proteins after treatment with IFN.

On the other hand, in the resistant cell lines, characteristic proteins with MW of 8070 and 5688 were observed in H4 chips. The quantity of the protein with MW of 5688 was increased by treatment of IFN (Fig. 6). Several types of proteins were commonly observed. As shown in Fig. 7, some proteins were not changed while the others were similarly increased by IFN treatment in both sensitive and resistant cell lines.

Database analysis of expressed proteins. By analysis using SWISS-PROT of ExPASy Molecular Biology Server, we identified 22 proteins showing homology with a specific MW in IFN-resistant cell lines (Table I). 


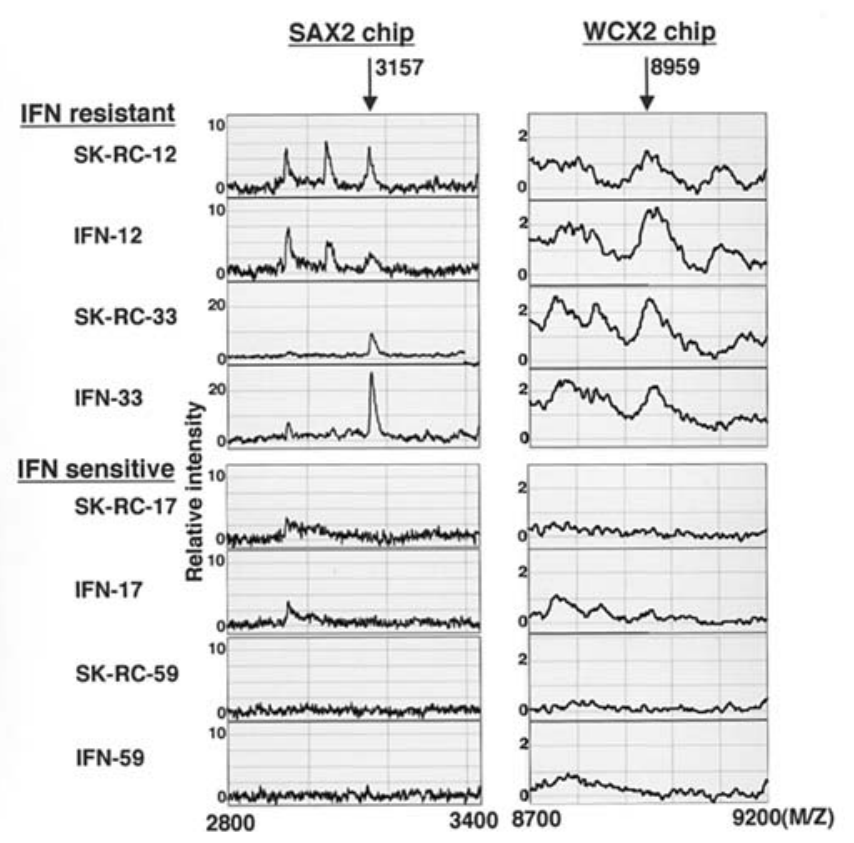

Figure 4. Representative spectrum examples from SELDI analyses of cultured renal cell lysate samples bound to SAX2 (left) and WCX2 (right) ProteinChip arrays. On the SAX2 chip, a peak of $3157 \mathrm{Da}$ (arrow) was present in the four IFN-resistant cell lysate samples but absent in the four IFN-sensitive samples. On the WCX2 chip, a peak of $8959 \mathrm{Da}$ (arrow) was present in the four IFNresistant cell lysate samples but absent in the four IFN-sensitive. IFN-12, $-33,-17$, and -59 indicate the cell lysate samples of SK-RC-12, $-33,-17$, and -59 cells obtained after treatment with IFN- $\alpha$. M/Z, mass/charge.

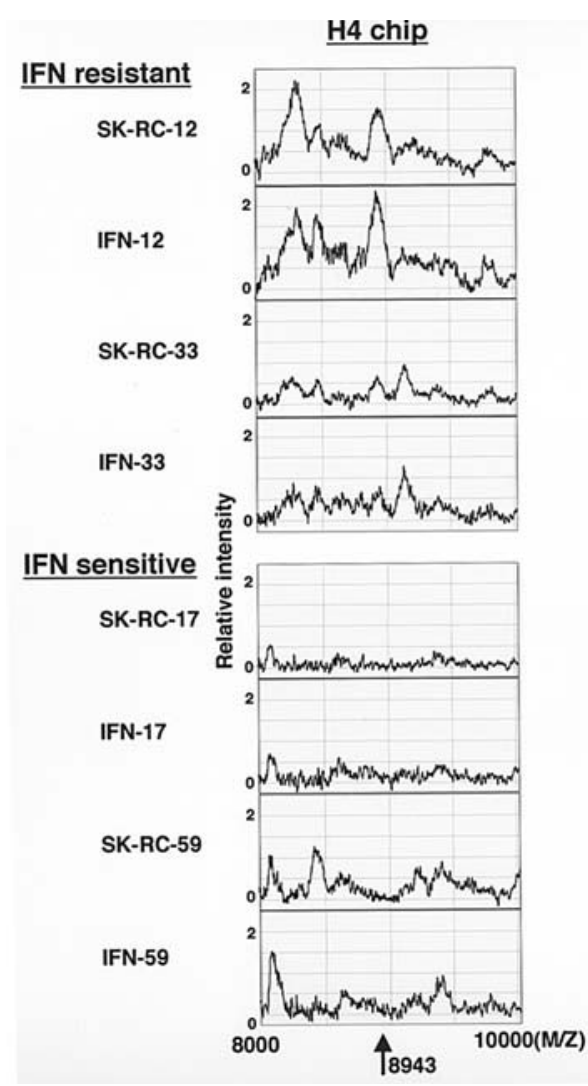

Figure 5. Representative spectrum examples of SELDI analysis of cultured renal cell lysate samples bound to H4 ProteinChip array. The peak of $8943 \mathrm{Da}$ (arrow) was present in the four IFN-resistant cell lysate samples but absent in the four IFN-sensitive samples. IFN-12, -33, 17 and -59 indicate the cell lysate samples obtained from cells of SK-RC-12, $-33,-17$ and -59 , respectively, after treatment with IFN. M/Z, mass/charge.

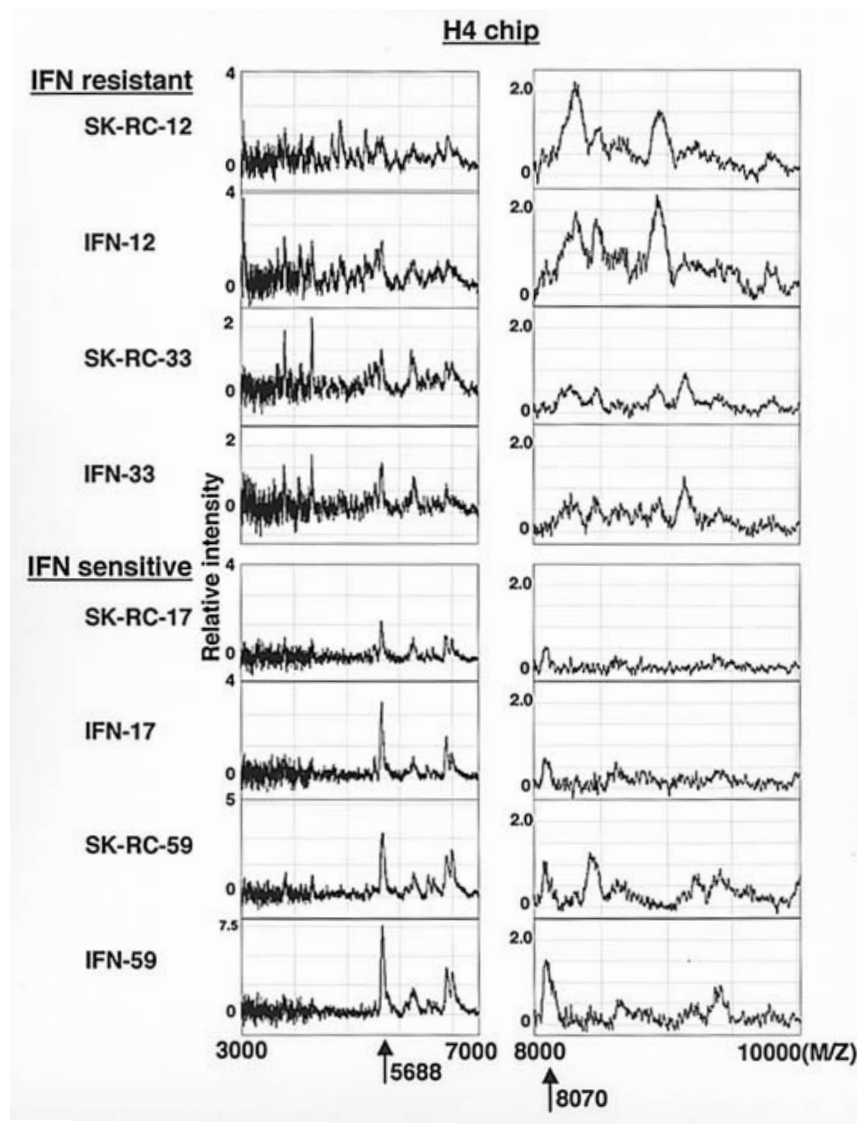

Figure 6. Representative spectrum examples from SELDI analyses of cultured renal cell lysate samples bound to an H4 ProteinChip array. The left chart shows enhancement of the peak of $5688 \mathrm{Da}$ (arrow) in the two IFNresistant cell lysate samples of IFN-17 and IFN-59, but not in the two IFNsensitive samples. The right chart shows the presence of a peak of $\sim 8070 \mathrm{Da}$ (arrow) in the four IFN-sensitive cell lysate samples and absence in the four IFN-resistant samples. IFN-12, -33, 17 and -59 indicate the cell lysate samples obtained from cells of SK-RC-12, -33, -17 and -59, respectively, after treatment with IFN. M/Z, mass/charge.

Furthermore, 12 proteins were detected in IFN-sensitive cell lines. The protein with MW of 1623 , detected commonly in both IFN-sensitive and resistant cell lines and showing intensified expression by IFN treatment, and was identified as Cerebellin (MW: 1632.80) and Melanotoropin $\alpha$ (MW: 1623.85) in terms of molecular weight (not shown in the table).

\section{Discussion}

IFN treatment for advanced RCC has been conducted without conclusive evidence of its efficacy. Bander et al reported a negative relation between an anti-gp160 monoclonal antibody they created and sensitivity to IFN 14), but there have been no reports on its clinical usefulness. Using cells and antibodies provided by Bander's Memorial-Sloan Kettering Cancer Center, we could not demonstrate this negative relation.

They also isolated the antigen corresponding to the antibody, and administered it to RCC that was not expressing this gene, but a relation to sensitivity could not be confirmed (14).

The signal transfer system from the IFN receptor is indicated to be involved with the direct sensitivity to IFN. 


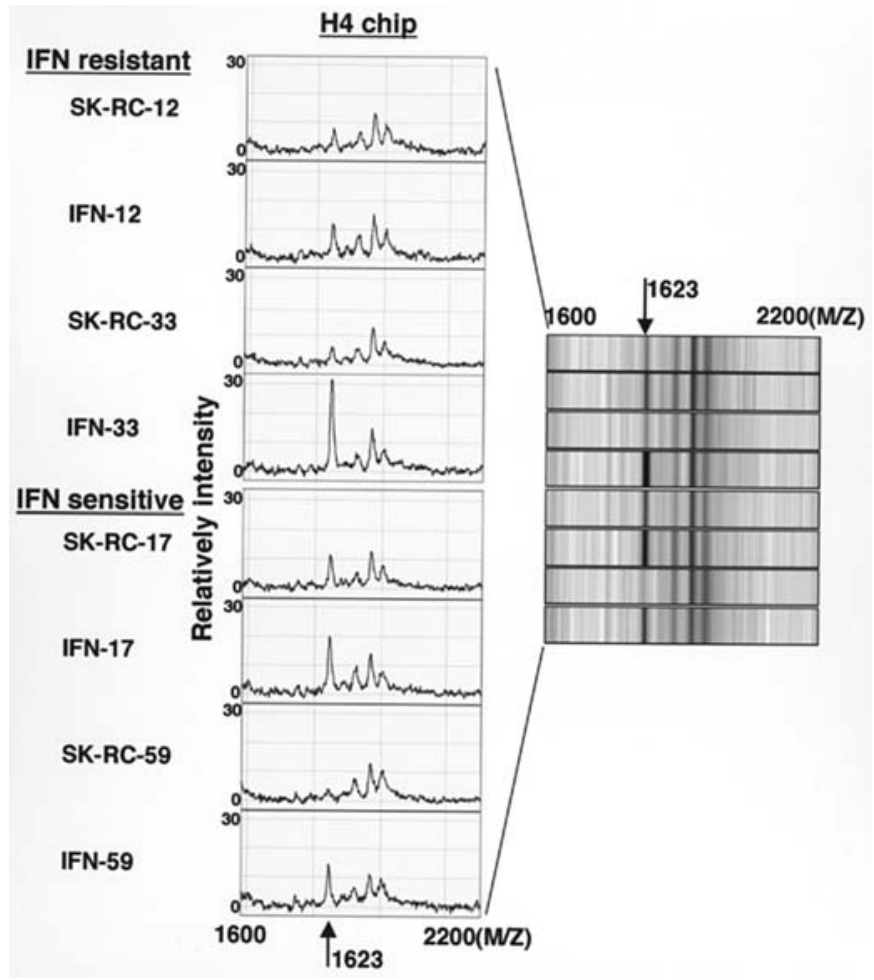

Figure 7. Representative spectrum examples from SELDI analyses of cultured renal cell lysate samples bound to an H4 ProteinChip array. A peak of $1623 \mathrm{Da}$ (arrow) was present in all cell lysate samples, and this peak protein was rich in both IFN-susceptible and IFN-resistant cell lines. IFN-12, -33, 17 and -59 indicate the cell lysate samples obtained from cells of SK-RC-12, -33, -17 and -59 , respectively, after treatment with IFN. M/Z, mass/charge.

The IFN- $\alpha$ receptor, Janus kinase (JAK 1) and Tyrosin kinase (Tyk2) that are non-receptor-type tyrosine phosphatase/kinase, and signal transducers and activators of transcription (STAT1, STAT2, ISGF3) that are transcription factors mediate the IFN signal transfer, and that these molecules form a complex and move to intranuclear. These molecules then bind to the transcriptional control site of a specific gene and control transcription of an IFN-induced gene cluster (15-17).

Although chronic myelogenous leukemia, multiple myeloma and melanoma are known as IFN-sensitive tumors, Sun et al (18) reported a lack of STAT1 molecules in resistant cell lines by separating IFN-resistant cell lines from cutaneous T-cell lymphoma cell lines that have sensitivity to IFN, and studied the association between sensitivity and the expression of molecules involved in those IFN signal transfers $(19,20)$.

The authors have assessed the identification of factors that regulate IFN sensitivity. For the expressed gene level, RT-PCR procedure was used to explore signaling molecules, Western blotting was used for the expressed protein level in our study. Our results revealed that there is no difference between resistant and sensitive cell lines for molecules involved in signal transfer.

These results suggest the existence of a signaling channel playing a role to inhibit cell proliferation other than the signaling channel previously reported. Therefore, we considered it important to search for a new molecule involved in IFNresistance.

As techniques available to identify an unknown molecule, there are the differential display method and microarray
Table I. Profiles of unique molecular-weight-homologous proteins involved in anti-proliferative effects of interferon- $\alpha$ on renal cell carcinoma cell lines.

\begin{tabular}{|c|c|c|}
\hline $\begin{array}{l}\text { MW of } \\
\text { detected } \\
\text { protein }\end{array}$ & $\begin{array}{l}\text { Accession } \\
\text { number }\end{array}$ & SWISS-PORT \\
\hline \multicolumn{3}{|l|}{ IFN resistant } \\
\hline \multirow[t]{5}{*}{3157} & P01166 & Somatostatin-28 \\
\hline & P18509 & $\begin{array}{l}\text { Pituitary adenylate cyclase } \\
\text { activating }\end{array}$ \\
\hline & P22466 & Galanin \\
\hline & P25063 & Signal transducer CD24 \\
\hline & P28799 & Paragranulin \\
\hline \multirow[t]{2}{*}{3993} & P01185 & Copeptin \\
\hline & P20366 & Neuropeptide K \\
\hline \multirow[t]{15}{*}{8943,8959} & O060356 & Protein P8 \\
\hline & O075711 & Scrapie-responsive protein 1 \\
\hline & P00747 & Activation peptide \\
\hline & P02655 & Apolipoprotein C-II \\
\hline & P02775 & ß-thromboglobulin \\
\hline & P07602 & Saposin B \\
\hline & P07602 & Saposin B-VAL \\
\hline & P10145 & Interleukin-8 \\
\hline & P18859 & ATP synthase coupling factor 6 \\
\hline & P13987 & CD59 glycoprotein \\
\hline & P29377 & Calbindin D9K \\
\hline & P35070 & Betacellulin \\
\hline & P55000 & $\begin{array}{l}\text { Secreted LY-6/UPAR related } \\
\text { protein } 1\end{array}$ \\
\hline & P80075 & Small inducible cytokine A8 \\
\hline & P80098 & Small inducible cytokine A7 \\
\hline \multicolumn{3}{|c|}{ IFN sensitive } \\
\hline \multirow[t]{3}{*}{5688} & P28799 & Granulin 1 \\
\hline & P28799 & Granulin 5 \\
\hline & P56381 & $\begin{array}{l}\text { ATP synthase } \varepsilon \text { chain, } \\
\text { mitochondrial }\end{array}$ \\
\hline \multirow[t]{10}{*}{8070} & O00626 & Small inducible cytokine A22 \\
\hline & O15239 & NADH-ubiquinone oxidoreductase \\
\hline & & MWFE subunit \\
\hline & P01350 & Gastrin 71 \\
\hline & P03928 & ATP synthase protein 8 \\
\hline & $\mathrm{P} 23411$ & 60 S ribosomal protein $\mathrm{L} 38$ \\
\hline & P59088 & Protein C21ORF85 \\
\hline & P78556 & Small inducible cytokine A20 \\
\hline & Q14138 & Hypothetical protein LIAA0125 \\
\hline & Q92583 & Small inducible cytokine A17 \\
\hline
\end{tabular}

technology for gene-level analysis, two-dimensional electrophoresis for protein-level analysis, and the technique 
combining protein chips and mass spectrometry used in the present study. However, since the microarray technology uses genes cloned previously and there are some genes that have not been cloned, not all genes can be studied with it. The two-dimensional electrophoresis also has some problems; a plentiful sample protein is required, there are some molecules that cannot be analyzed under certain buffer conditions, and unifying experimental condition is very difficult.

Since the differential display method has already been established in this course, and the technology with protein chips is relatively easy to use, first the differential display method was used. The results of analysis with the differential display method revealed two specific bands. We are now analyzing its expressional mechanism. We attempted to detect specific proteins by comparing the profiles of expressed protein in the present study. The results showed two candidate molecules for the marker that appears in IFN-sensitive cell lines and intensifies its expression by IFN treatment and four candidate molecules for a marker that can be detected only in resistant cell lines. Whether this protein has the molecular weight from the time it is synthesized, or when unbond by modification after translation remains unknown.

However, we consider the possibility of the original molecular weight, and searched for homologous proteins in terms of molecular weight in a protein database based on the detected molecular weight (Table I). Consequently, we found 22 molecules in resistant cell lines, and 12 molecules in sensitivity cell lines. However, the relation between IFN and signaling channel remains unclear and future investigation is necessary. Purification of protein, sequence of protein, and identification of molecular by analyses such as MS/MS are required.

Although candidate molecules for markers were detected in the present study, we have to evaluate it using clinical materials, for these molecules allow us to detect sensitivity to IFN using tissue materials removed by surgery, and to perform more aggressive treatment by confirming the sensitivity. Specific molecules that exist only in resistant cell lines are expected to be used not only as markers, but as target molecules that improve IFN sensitivity and increase the therapeutic effect by identifying its role in resistance to IFN.

In conclusion, using two IFN-sensitive and two IFNresistant cell lines of human RCC, we exhaustively analyzed proteins related to IFN. Two proteins specific for sensitive cell lines and 4 peaks that were specific for resistant cell lines were detected. These results suggest that the profiling technique combining protein chips and mass spectrometry is useful for searching for a wide variety of new markers. Furthermore, these proteins are expected to be useful as markers for predicting the sensitivity of the RCC to IFN treatment.

\section{Acknowledgments}

Thanks are due to Dr L.J. Old (Memorial-Sloan Kettering Cancer Center) for providing cells, and Kenji Saito and Yu Fukase of Ciphergen Biosystems.

\section{References}

1. De Kernion JB and Berry D: The diagnosis and treatment of renal cell carcinoma. Cancer 45: 1947-1956, 1980.

2. Patel NP and Lavengood RW: Renal cell cancer: natural history and results of treatment. J Urol 119: 722-726, 1997.

3. Wirth MP: Immunotherapy for metastatic renal cell carcinoma. Urol Clin North Am 20: 283-283, 1993.

4. Jenkins RE and Pennington SR: Arrays for protein expression profiling: towards a viable alternative to two-dimensional gel electrophoresis? Proteomics 1: 13-13, 2001.

5. Merchant $M$ and Weinberger SR: Recent advances in surfaceenhanced laser desorption/ionization-time of flight-mass spectrometry. Electrophoresis 21: 1164-1164, 2000.

6. Weinberger SR, Dalmasso EA and Fung ET: Current achievements using ProteinChip Array technology. Curr Opin Chem Biol 6: 86, 2002.

7. Fung ET, Wright GL Jr and Dalmasso EA: Proteomic strategies for biomarker identification: progress and challenges. Curr Opin Mol Ther 2: 643-643, 2000.

8. Adam B-L, Vlahou A, Semmes OJ and Wright GL Jr: Proteomic approaches to biomarker discovery in prostate and bladder cancers. Proteomics 1: 1264-1270, 2001.

9. Paweletz CP, Gillespie JW, Ornstein DK, Simone NL, Brown MR and Cole K: Rapid protein display profiling of cancer progression directly from human tissue using a protein biochip. Drug Dev Res 49: 34-42, 2000

10. Petricoin EF, Ardekani AM, Hitt BA, Levine PJ, Fusaro VA and Steinberg SM: Use of proteomic patterns in serum to identify ovarian cancer. Lancet 359: 572-577, 2002.

11. Xiao Z, Adam BL, Cazares LH, Clements MA, Davis JW and Schellhammer PF: Quantitation of serum prostate-specific membrane antigen by a novel protein biochip immunoassay discriminates benign from malignant prostate disease. Cancer Res 61: 6029-6033, 2001

12. Wright GL Jr, Cazares LH, Leung S-M, Nasim S, Adam B-L and Yip T-T: ProteinChip ${ }^{\circledR}$ surface enhanced laser desorption/ ionization (SELDI) mass spectrometry: a novel protein biochip technology for detection of prostate cancer biomarkers in complex protein mixtures. Prostate Cancer Prostatic Dis 2: 264-276, 1999.

13. Nanus DM, Preffer LM, Bander NH, Bahri S and Albino AP: Antiproliferative and antitumor effects of alpha-interferon in renal cell carcinomas: correlation with the expression of a kidney-associated differentiation glycoprotein. Cancer Res 50: 4190-4194, 1990.

14. Geng Y, Biffi A, Engelstein D, Ronch E, Faustini M and Lai HK: Expression of the kidney-associated differentiation glycoprotein gp160 and resistance to the antitumor effects of interferon alpha in renal cell carcinoma. Anticancer Res 18A: 1-7, 1998.

15. Darnell JE Jr, Kerr IM and Stark GM: Jak-STAT pathways and transcriptional activation in response to IFNs and other extracellular signaling proteins. Science 264: 1415-1421, 1994.

16. Ihle J: STATs: signal transducers and activators of transcription. Cell 84: 331-334, 1996.

17. Schindler C and Darnell JE Jr: Transcriptional responses to polypeptide ligands: the JAK-STAT pathway. Annu Rev Biochem 64: 621-651, 1995.

18. Sun WH, Pabon C, Alsayed Y, Huang PP, Jandeska S and Uddin S: Interferon- $\alpha$ resistance in a cutaneous T-cell lymphoma cell line is associated with lack of STAT1 expression. Blood 91: 570-576, 1998.

19. Pansky A, Hildebrand P, Fasler-Kan E, Baselgia L, Ketterer S and Belinger C: Defective JAK-STAT signal transduction pathway in melanoma cells resistant to growth inhibition by interferon- $\alpha$. Int J Cancer 85: 720-725, 2000.

20. Wong LH, Krauer KG, Hatzinisiriou I, Estcourt MJ, Hersey P and Tam ND: Interferon-resistant human melanoma cells are deficient in ISGF3 components, STAT1, STAT2, and p48ISGF3 $\gamma$. J Biol Chem 272: 28779-28785, 1997. 